\title{
Look out before polypectomy in patients with diverticular disease - a case of a large, inverted diverticulum of the colon resembling a pedunculated polyp
}

\author{
Omero Alessandro Paoluzi MD, Claudio Tosti MD, Fabio Andrei MD, \\ Italo Stroppa MD, Francesco Pallone MD
}

OA Paoluzi, C Tosti, F Andrei, I Stroppa, F Pallone. Look out before polypectomy in patients with diverticular disease - a case of a large, inverted diverticulum of the colon resembling a pedunculated polyp. Can J Gastroenterol 2010;24(1):61-63.

Diverticular disease of the colon may be responsible for abdominal symptoms requiring colonoscopy, which may reveal the presence of concomitant polyps. A polyp found during colonoscopy in patients with colonic diverticular disease may be removed by endoscopic polypectomy with electrosurgical snare, a procedure associated with an incidence of perforation of less than $0.05 \%$. The risk of such a complication may be higher in the event of an inverted colonic diverticulum, which may be misinterpreted as a polypoid lesion at colonoscopy. To date, fewer than 20 cases of inverted colonic diverticula, diagnosed at colonoscopy or following air contrast barium enema, have been reported in the literature. The present report describes a 68-year-old woman who underwent a screening colonoscopy, which revealed a voluminous pedunculated polyp that was recognized to be an inverted giant colonic diverticulum before endoscopic polypectomy.

Key Words: Colonic diverticulum; Colonic polyp; Colonoscopy; Polypectomy

$\mathrm{D}$ iverticular disease of the colon, a condition frequently observed in clinical practice, may be responsible for abdominal symptoms requiring colonoscopy. Colonoscopy may reveal the presence of polyps, often adenomas concomitant with diverticular disease (1-3), which may be removed by endoscopic polypectomy. This procedure has been estimated to account for approximately $50 \%$ of the cases of perforation reported during colonoscopy, the incidence of which has been reported to be less than $0.05 \%$ (4-6). The risk of such a complication is higher in the event of an inverted colonic diverticulum, which may be misinterpreted as a polypoid lesion at colonoscopy. To date, fewer than 20 cases of inverted colonic diverticula, diagnosed at colonoscopy or following air contrast barium enema, have been reported in the literature (7-14).

The present report describes a patient who underwent a screening colonoscopy, which revealed a voluminous, pedunculated polyp recognized to be an inverted giant colonic diverticulum before endoscopic polypectomy.
Soyez vigilant avant une polypectomie chez les patients ayant une maladie diverticulaire : Le cas d'un gros diverticule inversé du colon ressemblant à un polype pédonculé

La maladie diverticulaire du colon peut être responsable de symptômes abdominaux exigeant une coloscopie, laquelle peut révéler la présence de polypes concomitants. Un polype trouvé pendant la coloscopie chez des patients ayant une maladie diverticulaire du côlon peut être extrait par polypectomie endoscopique au moyen d'une excision électrochirurgicale à l'anse, une intervention s'associant à un risque de perforation inférieur à $0,05 \%$. Le risque d'une telle complication peut être plus élevé en cas de diverticule colique inversé qui, à la coloscopie, peut être confondu avec une lésion polypoïde. Jusqu'à présent, moins de 20 cas de diverticule colique inversé, diagnostiqués au moment de la coloscopie ou après un lavement baryté de contraste, sont déclarés dans les publications. Le présent rapport décrit le cas d'une femme de 68 ans qui a subi une coloscopie de dépistage, laquelle a révélé un polype pédonculé volumineux diagnostiqué comme un diverticule colique géant inversé avant la polypectomie endoscopique.

Gastrointestinal Unit, Centre of Excellence for the Study of Complex and Multifactorial Diseases, Department of Internal Medicine,

Tor Vergata University, Rome, Italy

Correspondence: Dr Omero Alessandro Paoluzi, UOC di Gastroenterologia, Dipartimento di Medicina Interna, Università Tor Vergata, Viale

Oxford 81, 00133 Roma, Italy. Telephone 39-06-20900969, fax 39-06-20903738, e-mail omeroalessandro.paoluzi@ptvonline.it

Received for publication April 21, 2009. Accepted May 2, 2009 

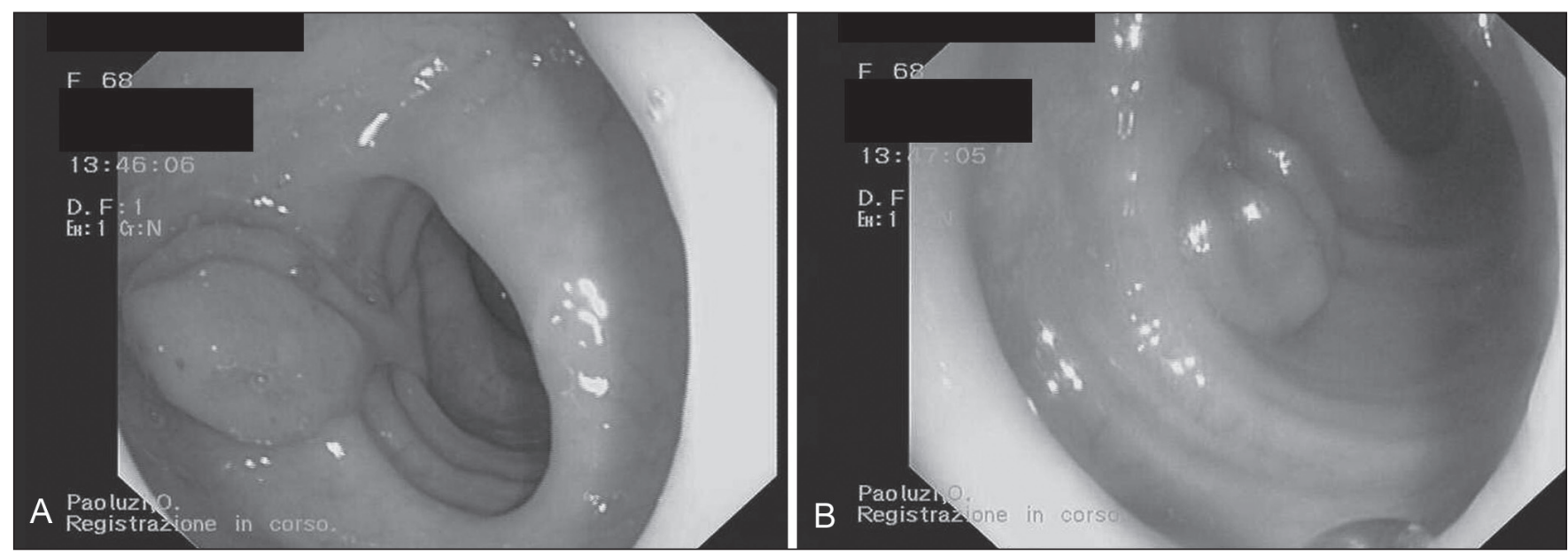

Figure 1) Two views (A and B) of a large, inverted diverticulum of the colon resembling a pedunculated polyp

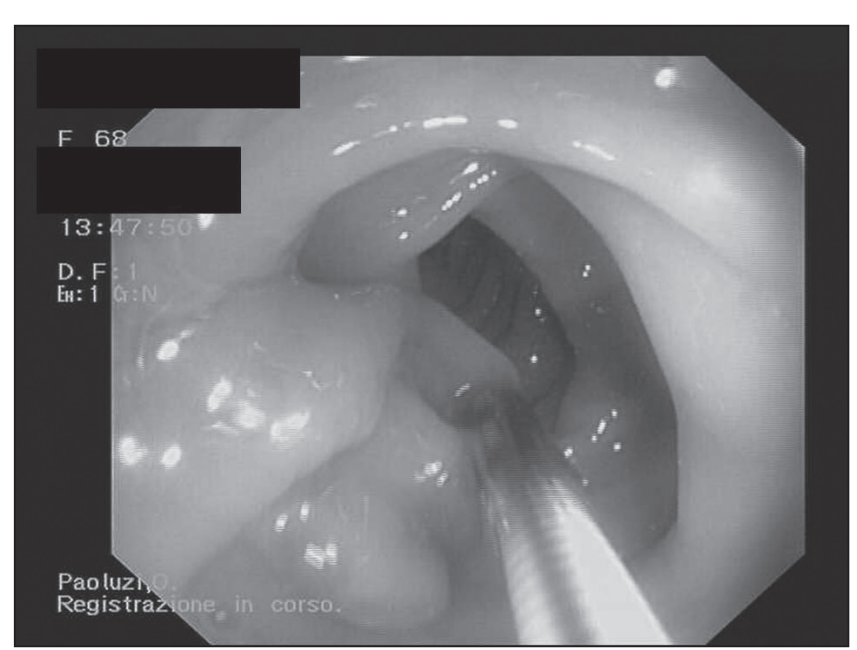

Figure 2) The lesion moved by biopsy forceps. The neck of the diverticulum resembled a long, thin stalk and the head appeared flat

where the polypoid lesion was located. Because standard assessments of coagulation and complete blood counts were within the normal ranges, removal of the polypoid lesion by means of endoscopic polypectomy with diathermal coagulation was scheduled. However, when in contact and moved with biopsy forceps, the head of the polyp appeared soft and empty (Figure 2). When delicate pressure was applied, the polypoid lesion appeared reduced in size, as if it was pushed out beyond the colonic wall. Polypectomy was abandoned and three biopsy specimens were collected from the head of the lesion to define its nature. Histology revealed the presence of hyperplastic epithelium and mild inflammatory changes in the normal colonic mucosa - a finding consistent with a diagnosis of inverted diverticulum of the colon.

\section{DISCUSSION}

The present report described endoscopic findings with regard to a colonic lesion, first diagnosed as a polyp, possibly an adenoma; however, based on macroscopic features and histological findings, the lesion was subsequently revealed to be an inverted diverticulum of the colon. The relevance of this condition seems to reside in the apparent difficulty in reaching an appropriate diagnosis in clinical practice because, to date, fewer than 20 cases have been reported in the literature (7-14). Of these, six were correctly diagnosed on radiology $(11,14,15)$ and five at colonoscopy (11), while the remaining eight were diagnosed following histological assessment of colonic specimens after surgery in five cases and following endoscopic polypectomy in three. These data have led to speculation that there is a high possibility of missing an inverted colonic diverticulum, or misdiagnosing this condition as a polyp at radiology and colonoscopy. This outcome appears more likely when the lesion is large, such as the one described in the present case (greater than $2 \mathrm{~cm}$ in size), and strongly resembles a pedunculated polyp. This latter morphology has previously been observed in only two large $(3 \mathrm{~cm})$ inverted colonic diverticulae $(10,14)$, one of which appeared as a pedunculated polyp (10), and is very different from most cases of inverted diverticulum described to date, which were only a few millimetres in size.

Although little data regarding the incidence of complications associated with inverted colonic diverticulum have been reported in the literature, it is tempting to hypothesize that an incorrect diagnosis of this condition, especially when resembling a polyp, may be responsible for severe complications such as perforation following endoscopic polypectomy with electrosurgical snare. Therefore, prompt diagnosis of an inverted colonic diverticulum during colonoscopy appears to be crucial. To more easily define a differential diagnosis between an inverted colonic diverticulum and common true polyps, it may be worthwhile to attempt to induce eversion of the diverticulum by air insufflation, as observed during radiological examination (11) or colonoscopy (7), or by probing the lesion with biopsy forceps and gently pushing it outside the colonic wall, as suggested by Triadafilopoulos (8). These manoeuvres seem to be more successful in cases of a small diverticulum, but may fail in cases of a large inverted colonic diverticulum as, in part, occurred in the present case. In these occurrences, collection of biopsy specimens may reveal a normal mucosa, a finding consistent with a diagnosis of diverticulum. Recognizing that the wall of a diverticulum consists only of mucosa, biopsies should be performed with considerable caution. Indeed, biopsy specimens in the present case were collected without complications, 
a finding consistent with other reports (7). Colonic perforation following biopsy collection from an inverted colonic diverticulum has been described in only one case (9). Thus, the risk of colonic perforation following biopsy collection from a large, inverted colonic diverticulum appears to be low.

\section{CONCLUSION}

The present report highlights the possibility of finding an inverted colonic diverticulum during colonoscopy. This possibility must be considered carefully to reach a correct diagnosis and avoid potentially dangerous procedures such as endoscopic polypectomy.

\section{REFERENCES}

1. Stefansson T, Ekbom A, Sparen P, Pahlman L. Increased risk of left sided colon cancer in patients with diverticular disease. Gut 1993;34:499-502.

2. Morini S, Hassan C, Zullo A, et al. Diverticular disease as a risk factor for sigmoid colon adenomas. Dig Liver Dis 2002;34:635-9.

3. Kieff BJ, Eckert GJ, Imperiale TF. Is diverticulosis associated with colorectal neoplasia? A cross-sectional colonoscopic study. Am J Gastroenterol 2004:99:2007-11.

4. Araghizadeh FY, Timmcke AE, Opelka FG, Hicks TC, Beck DE. Colonoscopic perforations. Dis Colon Rectum 2001;44:713-6.
5. Korman LY, Overholt BF, Box T, Winker CK. Perforation during colonoscopy in endoscopic ambulatory surgical centers. Gastrointest Endosc 2003;58:554-7.

6. Cobb WS, Heniford BT, Sigmon LB, et al. Colonoscopic perforations: Incidence, management, and outcomes. Am Surg 2004;70:750-7.

7. Yusuf SI, Grant C. Inverted colonic diverticulum: A rare finding in a common condition? Gastrointest Endosc 2000;52:111-5.

8. Triadafilopoulos G. Images in clinical medicine. Inverted colonic diverticulum. N Engl J Med 1999;341:1508.

9. Hollander E, David G. Inverted sigmoid diverticulum simulating polyps. Orv Hetil 1993;134:639-40.

10. Dumas O, Jouffre C, Desportes R, Etaix JP, Barthelemy C, Audigier JC. Inverted sigmoid diverticulum: A misleading polyp. Gastrointest Endosc 1991;37:587-8.

11. Glick SN. Inverted colonic diverticulum: Air contrast barium enema findings in six cases. Am J Roentgenol 1991;156:961-4.

12. Ladas SD, Prigouris SP, Pantelidaki C, Raptis A. Endoscopic removal of inverted sigmoid diverticulum - is it a dangerous procedure? Endoscopy 1989;21:243-4.

13. Shah AN, Mazza BR. The detection of an inverted diverticulum by colonoscopy. Gastrointest Endosc 1982;28:188-9.

14. Freeny PC, Walker JH. Inverted diverticula of the gastrointestinal tract. Gastrointest Radiol 1979;4:57-9.

15. Posner R, Solomon A. Dilemma of an inverted cecal diverticulum simulating a pedunculated polyp: CT appearance. Abdom Imaging 1995;20:440-1. 


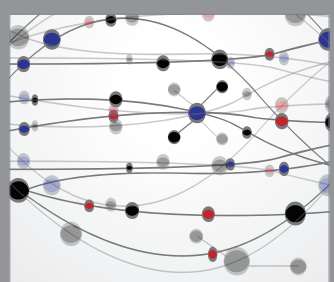

The Scientific World Journal
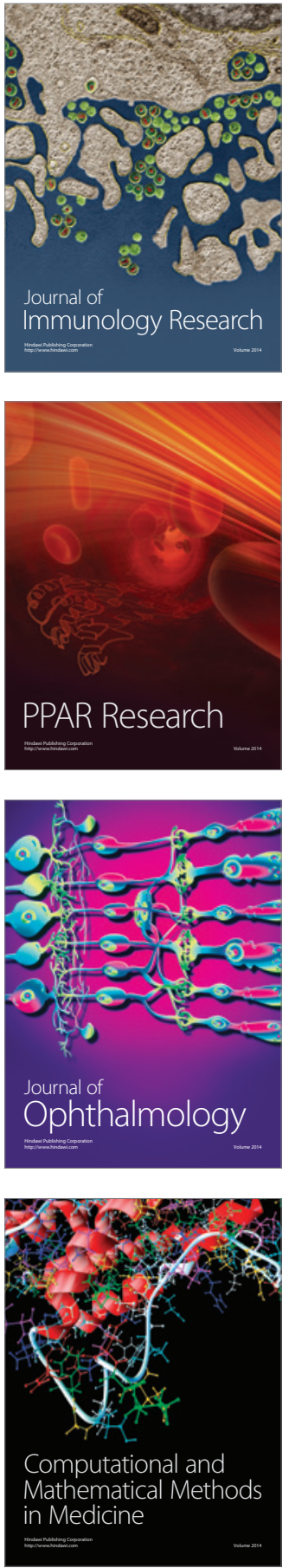

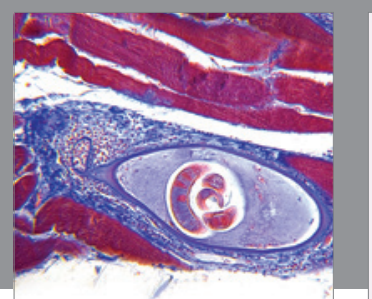

Gastroenterology Research and Practice

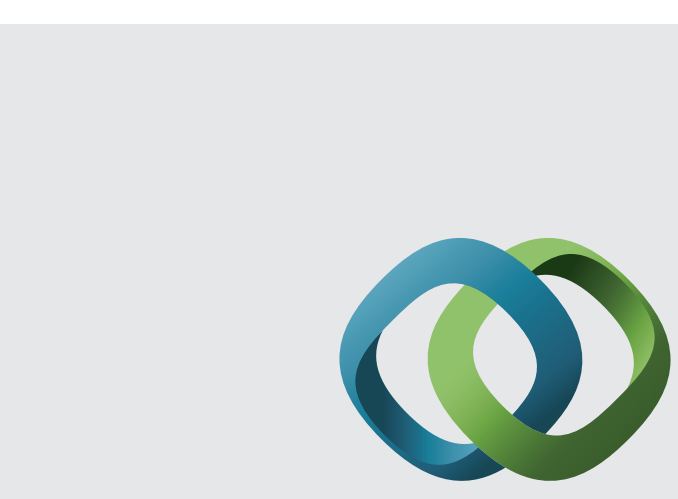

\section{Hindawi}

Submit your manuscripts at

http://www.hindawi.com
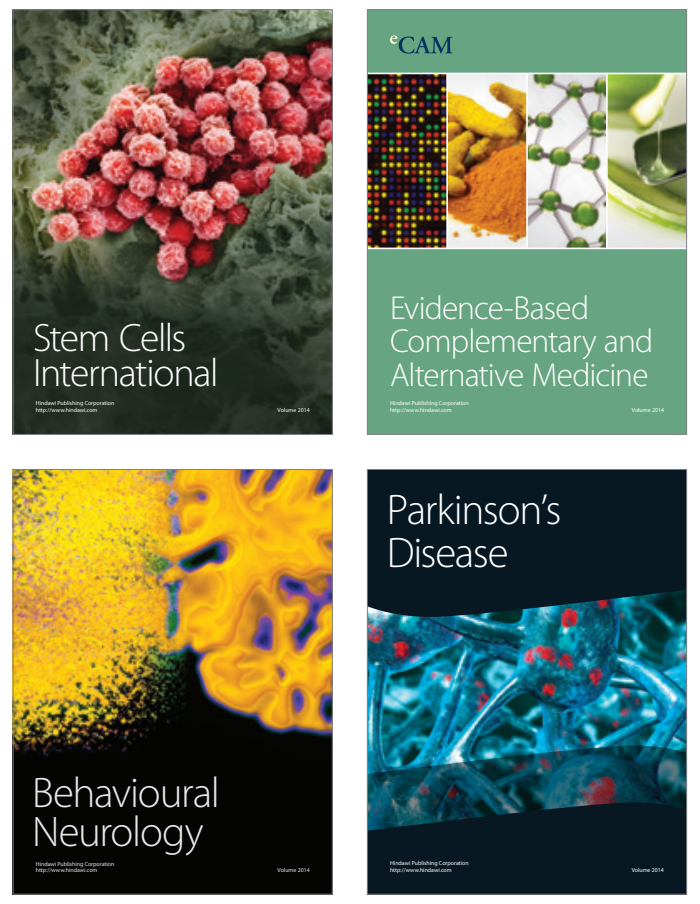
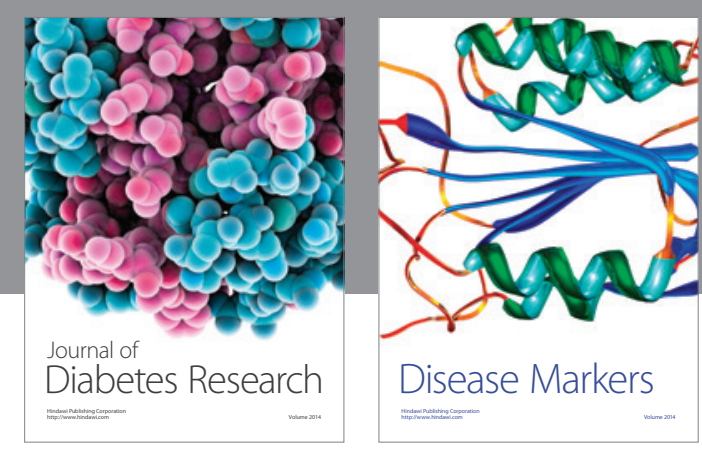

Disease Markers
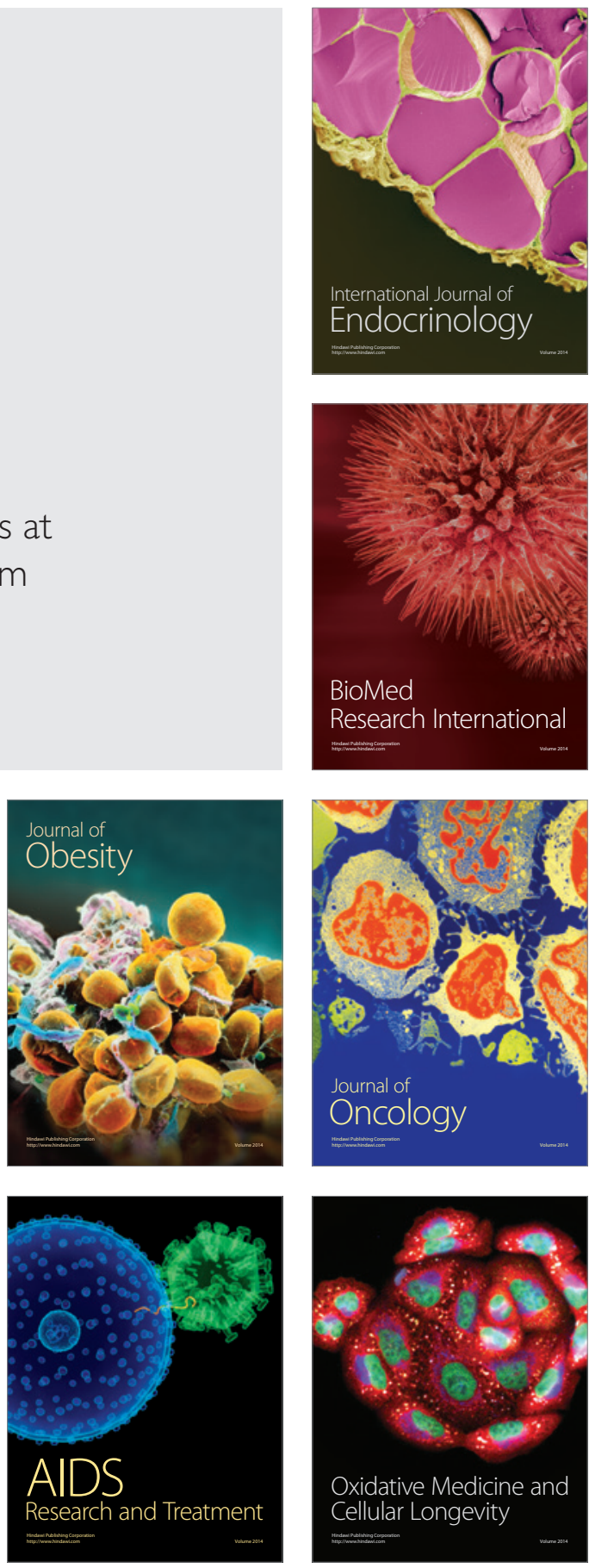